\title{
Young men and the morning after: a missed opportunity for emergency contraception provision?
}

\author{
Sheree M Schrager, ${ }^{1}$ Johanna Olson, ${ }^{2}$ Meera Beharry, ${ }^{3}$ Marvin Belzer, ${ }^{4}$ \\ Katherine Goldsich, ${ }^{5}$ Mona Desai, ${ }^{6}$ Leslie F Clark ${ }^{7}$
}

For numbered affiliations see end of article.

\section{Correspondence to}

Dr Sheree M Schrager, Children's Hospital Los Angeles, 5000 Sunset Blvd, Suite 701 Los Angeles, CA 90027, USA; sschrager@chla.usc.edu

Received 25 February 2013 Revised 10 October 2013 Accepted 6 December 2013 Published Online First 24 January 2014

\section{CrossMark}

To cite: Schrager SM, Olson J, Beharry M, et al. I Fam Plann Reprod Health Care 2015;41:33-37.

\begin{abstract}
Objectives Although adolescents and young adults of lower socioeconomic status (SES) are disproportionately affected by unintended pregnancies, research on experiences with emergency contraception (EC) in this population has lagged. Furthermore, it is unclear whether EC-related knowledge and behaviour varies between young men and women. This study investigated knowledge, attitudes and experiences with EC among low SES young men and women aged 18-25 years.
\end{abstract}

Methods One hundred and ninety-eight new enrollees at two Los Angeles primary medical care clinics completed surveys about their knowledge, past use and likelihood of using EC. Chi square $\left(\chi^{2}\right)$ and regression analyses assessed gender differences in knowledge and attitudes.

Results Women were more likely than men to accurately answer questions about EC and its use. Across both sexes, accurate knowledge predicted future willingness to use EC. Only half the women and a third of men knew that EC could be directly dispensed by pharmacists; even fewer knew that the legal access age for EC was 17 years $(13 \%)$ or that men could access EC from pharmacies for their female partners (24\%). Although respondents most commonly reported that friends were their source of current information about EC, both men and women chose health care professionals as their desired source of future information about EC.

Conclusions Young men in this sample were significantly less knowledgeable than young women about EC. Educating young men about $\mathrm{EC}$ by health care providers during routine visits may be a unique opportunity to increase EC knowledge, access and use among low-income young couples to decrease undesired pregnancies.

\section{Key message points}

- Young men were significantly less knowledgeable about emergency contraception (EC) than young women.

- Both young men and young women expressed a desire to learn about EC from their health care providers.

- Including young men in the education target population may be an effective strategy to increase EC use.

\section{BACKGROUND}

The promise first made two decades ago by the proponents of emergency contraception (EC), of its potential to prevent half of the abortions and unintended pregnancies in the USA each year, remains largely unfulfilled. ${ }^{1}{ }^{2}$ Levonorgestrel (Plan B) has been the primary agent used for EC since its introduction in 2000 and has been demonstrated to be efficacious, safe-and easy to use. ${ }^{3}$ Data from the National Survey of Family Growth show relatively low rates of EC use among young sexually active women $(14 \%$ for 15-19-year-olds and 23\% for 2024-year-olds). EC use was lower for older women, among those without a college education, and for African American women. $^{4}$

The adverse health and economic consequences associated with unplanned pregnancies among older adolescents may be greater among low socioeconomic status (SES) populations, where unwanted pregnancy rates are higher than in other populations. ${ }^{5}$ Yet pharmacies in lowincome neighbourhoods present barriers to young people accessing EC. ${ }^{6}$ 
Pharmacists' knowledge of EC regulations, for example, may adversely affect adolescents' access to EC: a telephone survey conducted in five states documented that pharmacists in low-income communities incorrectly reported higher ages for legal over-the-counter access and were less willing to provide EC to a 17-year-old caller than pharmacists in affluent neighbourhoods, even though the pharmacies in low-income and affluent areas reported equal availability of EC. ${ }^{6}$

Despite such barriers, contraceptive use among young adults has been shown to increase when male partners are involved in contraceptive decisionmaking. ${ }^{7}$ Although over-the-counter purchasing laws do not restrict by gender, barriers to EC use emerge via men's lack of knowledge about EC and its accessibility. In a study of adults' knowledge of EC, men were less likely than women to know about men's access to EC through pharmacies. ${ }^{7}$ More than half of the men felt they should offer to buy EC if needed, and more than two-thirds believed that their purchases would successfully prevent unplanned pregnancies; however, not perceiving a need, not knowing how to obtain EC, and preferring women to obtain EC were frequently cited barriers to male EC purchase. ${ }^{8}$ Despite evidence from college samples that educating men about EC results in greater support for their female partners' use of EC, ${ }^{9}$ male partners remain a largely overlooked audience for education efforts.

Furthermore, no research has examined the knowledge and attitudes toward EC among young men and women of lower SES, a population disproportionately affected by unintended pregnancies. ${ }^{5}$ To address this gap in knowledge, we conducted a survey to examine gender differences in the knowledge, attitudes and experiences with EC among low SES older adolescents and young adults receiving medical care in two urban clinics in Los Angeles.

\section{METHODS}

Between 2008 and 2009, a convenience sample of 101 males and 97 females was recruited. Subjects were either new enrollees of the Los Angeles Job Corps training facility who received medical screenings or young adult clients of the Saban Free Clinic, a site that offers service for individuals of low SES (defined as income less than $133 \%$ of the Federal poverty level). Potentially eligible subjects were identified by the clinic staff and were told about the study by the primary investigator or research assistant. Subjects were eligible for inclusion if they were newly registered in one of the study sites, were 18-25 years old, and were able to understand without assistance the English-language study information sheet and survey instrument. Respondents completed a 50-item questionnaire and received a $\$ 10$ gift card to a local retail establishment. The study was approved by the
Committee on Clinical Investigations at Children's Hospital Los Angeles.

Measures were adapted from a Kaiser Family Foundation survey instrument ${ }^{10}$ and modified to simplify language and minimise potential order effects. Demographic information collected included age in years, gender $($ Female $=1$, Male $=0)$, race/ethnicity (White =1, Black=2, Hispanic $=3, \quad$ Asian/Pacific Islander $=4$, Other $=5$, Multiethnic $=6$ ) and educational attainment level (High school or more $=1$, Less than high school=0). Knowledge of EC facts included four items: "If a woman has just had sex without birth control or thinks her birth control may have failed, is there anything she can do afterward to prevent pregnancy?" (Yes/No); "Emergency contraceptive pills are used primarily to prevent pregnancy" (True/False); "Emergency contraceptive pills are another term for RU-486, the 'abortion pill'” (True/ False) and "How many days after the sex without birth control can [a woman] use emergency contraceptive pills to prevent pregnancy?" (respondent wrote in the number of days). A composite knowledge accuracy score, ranging from 0 to 4 , was created by summing accurate responses to these items. Attitudes toward EC were designed to probe personal beliefs about use of contraception and contraceptive decision-making, and included Likert-type questions such as "If you were to have sex without birth control, or your regular birth control might have failed and you wanted to prevent a pregnancy, how likely would you be to take, or suggest your partner take EC if it was free" or "if you had to buy it?" Response options ranged from 1 (Very unlikely) to 4 (Very likely). Sexual experience and experience with EC was recoded as a binary measure $(\mathrm{No}=0$, Yes $=1)$ determined from the question: "Have you or any of your partners ever taken emergency contraceptive pills?" Demographic, EC knowledge and EC attitude items are presented overall and by gender in Table 1.

Statistical analyses were conducted using SPSS V.17 (IBM, Armonk, NY, USA). Descriptive statistics were used to characterise the demographic makeup of the sample. Bivariate tests of differences by gender and prior sexual activity in dichotomous EC-related awareness and behaviour outcomes (including prior use of EC and recommending EC to a friend) were conducted with $\chi^{2}$ tests. Linear and logistic regression analyses were used to assess the relationship between gender and knowledge, attitudes and experiences with EC, controlling for other socio-demographic factors.

\section{RESULTS}

Forty-nine per cent of the sample was female; the mean age was $20.4 \pm 1.9$ years (males: 20.6 2.0 , females: $20.2 \pm 1.8$ ) and $72 \%$ had not completed high school. Sixty-one per cent of respondents were Hispanic, with 13\% White, 16\% African American, and $6 \%$ Other. Compared to males, females were 
Table 1 Demographic and emergency contraception knowledge variables by gender

\begin{tabular}{|c|c|c|c|c|}
\hline Variable & Males $(n=101)$ & Females $(n=97)$ & Total $(n=198)$ & $p$ \\
\hline \multicolumn{5}{|l|}{ Demographics } \\
\hline Mean (range 18-24) age (years) & 20.5 & 20.2 & 20.4 & 0.18 \\
\hline \multicolumn{5}{|l|}{ Ethnicity } \\
\hline White & $19 \%$ & $7 \%$ & $13 \%$ & 0.10 \\
\hline Black & $18 \%$ & $15 \%$ & $16 \%$ & \\
\hline Hispanic & $52 \%$ & $70 \%$ & $61 \%$ & \\
\hline Multiethnic/Other & $11 \%$ & $8 \%$ & $10 \%$ & \\
\hline High school graduate & $30 \%$ & $26 \%$ & $28 \%$ & 0.51 \\
\hline \multicolumn{5}{|l|}{ Knowledge of EC facts } \\
\hline Total score (range $0-4$ ) & 1.97 & 2.85 & 2.40 & $<0.001$ \\
\hline Aware that EC pill prevents pregnancy & $77 \%$ & $91 \%$ & $84 \%$ & 0.01 \\
\hline Awareness of a postcoital method & $67 \%$ & $87 \%$ & $77 \%$ & 0.001 \\
\hline Distinguish between mifepristone and EC & $46 \%$ & $74 \%$ & $60 \%$ & $<0.001$ \\
\hline 3-5 day window postcoital effectiveness & $19 \%$ & $42 \%$ & $31 \%$ & 0.001 \\
\hline \multicolumn{5}{|l|}{ Knowledge of EC access } \\
\hline Women over 18 years can get EC directly from pharmacist without doctor visit & $31 \%$ & $49 \%$ & $41 \%$ & 0.03 \\
\hline Women under 18 years can get EC directly from pharmacist without doctor visit & $8 \%$ & $18 \%$ & $13 \%$ & 0.03 \\
\hline Men can get EC for partner's use directly from pharmacist & $26 \%$ & $21 \%$ & $24 \%$ & 0.73 \\
\hline
\end{tabular}

EC, emergency contraception.

significantly more likely to have been sexually active [ $91 \%$ vs $79 \%$, respectively; $\left.\chi^{2}(1)=5.24, p<0.05\right]$.

Respondents of both sexes were significantly more likely to know about EC if they had prior sexual experience $\left[89.2 \%\right.$ vs $\left.56.7 \%, \chi^{2}(1)=20.1, p<0.01\right]$. Among sexually experienced respondents, nearly $18 \%$ of males reported they had a partner who had used EC, while over $36 \%$ of female respondents reported prior use themselves $\left[\chi^{2}(1)=7.25, p<0.01\right]$. Across the sample, women were more likely than men to report recommending EC to someone else in the past [50\% vs $\left.32 \% ; \chi^{2}(1)=6.0, p<0.05\right]$.

As presented in Table 1 , young women were more likely than men to respond accurately to questions about EC and its use. Controlling for age and ethnicity, a linear regression analysis showed that being male $[\beta=-0.31, F(1,197)=4.91, p<0.001]$, having less than a high school education $[\beta=-0.14, F(1,197)$ $=2.18, p<0.05]$ and being naïve to $\mathrm{EC}$ use $[\beta=-0.36$, $\mathrm{F}(1,197)=5.76, p<0.001]$ were associated with less accurate knowledge about EC and its use. Logistic regressions controlling for age, ethnicity and education found that across both sexes, accurate knowledge of EC and its use predicted youths' willingness to use EC if they could acquire it for free $(\mathrm{OR}=2.16$, $p<0.05,95 \%$ CI $1.71-4.02)$ or if it was provided to them in advance of needing it $(\mathrm{OR}=2.08, p<0.05$, 95\% CI 1.44-3.01). Half the women and one-third of the men were aware that EC could be directly dispensed by pharmacists; even fewer knew that the access age is 17 years or that men could access EC from pharmacists for their female partners. Friends were listed as the most common source of current information about EC (Figure 1). Health care professionals were the most preferred source of future information for both sexes, although significantly fewer men than women had previously received information about EC from their health care provider $[13 \%$ vs $\left.47 \%, \chi^{2}(1)=23.1, p<0.001\right]$.

\section{DISCUSSION}

This study assessed gender differences with regard to EC in a low SES sample of young adults. Thirty-six per cent of sexually active females aged 18-24 years in our low-educated sample reported previous EC use. This is higher than the $23 \%$ of $20-24$-year-olds reporting EC use in the National Survey of Family Growth. ${ }^{4}$ This finding may be due to the Los Angeles study setting and/or recruitment of young people from Job Corps and youth seeking care from a clinic serving low-income populations.

In line with previous research, ${ }^{11}$ male respondents in our study knew significantly less about EC than women in all knowledge categories. However, significant knowledge gaps existed for both sexes (such as the window for effectiveness and the ability to access EC from pharmacists directly) that could affect EC use rates. Although a majority of subjects reported that their friends were currently their primary source of EC knowledge, health care professionals were by far the most common preference for obtaining future information about EC. Accurate knowledge about EC and its use was associated with future willingness to use EC, suggesting that education about EC may be an important avenue for future family planning interventions. 


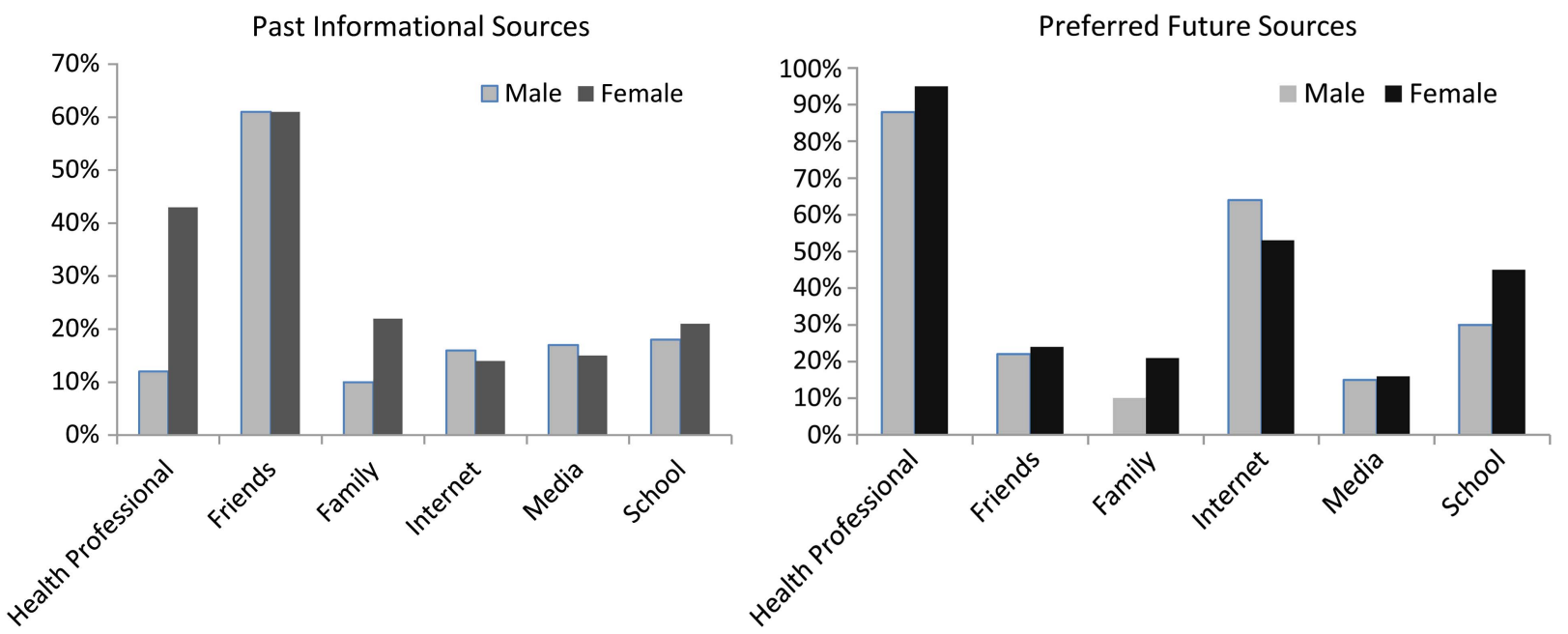

Figure 1 Past and preferred future sources of information about emergency contraception.

A position paper on EC published by the Society for Adolescent Medicine in 2004 has made clear recommendations for physicians who serve young people regarding their responsibility to inform patients about EC as a pregnancy prevention strategy. ${ }^{12}$ Establishing and adhering to recommended EC protocols (including advance provision of EC and communication to partnering pharmacies) is critical. Including young men in the education target population may also be an effective strategy to increase EC use, particularly in light of our finding that young men were less likely to have received information about EC from their health care providers compared to young women.

This study of a diverse sample of nearly 200 adolescents represents an important contribution to the literature on EC. Nonetheless, there are several limitations to our study. First, as our sample consisted of youth accessing medical screenings or care, results may not generalise to adolescents who are unable or choose not to access medical care. Generalisability may also be limited to populations of a different demographic makeup and non-English-speaking populations. Second, our findings were based on selfreported responses that may be open to certain biases, such as self-presentational bias. Third, the survey was adapted from a previously developed instrument ${ }^{10}$ and inherited any weaknesses present in that survey (e.g. assessing history of sexual intercourse after having previously referenced intercourse in the context of vaginal sex). Finally, although we did ask questions pertaining to EC-related behaviour (e.g. prior use of EC), we did not assess detailed information to contextualise EC use, such as frequency or timing of use, nor did we obtain any measures of behaviour other than self-report.

The promise of EC's potential to prevent abortions and unintended pregnancies remains unfulfilled in part due to barriers including lack of knowledge and awareness of how to access EC. Our sample represented low SES young people for whom unintended pregnancies are associated with poor outcomes and who live in neighbourhoods where pharmacists may be unwilling to dispense EC to adolescents. ${ }^{6}$ Given this, health care professionals remain a critical portal for conveying information about EC and its access to young people.

\section{Author affiliations}

${ }^{1}$ Behavioral Research Administrator, Division of Adolescent Medicine, Children's Hospital Los Angeles, Los Angeles, CA, USA

${ }^{2}$ Assistant Professor, Division of Adolescent Medicine, Children's Hospital Los Angeles and Department of Pediatrics, Keck School of Medicine, University of Southern California, Los Angeles, CA, USA

${ }^{3}$ Assistant Professor, Department of Pediatrics, McLane Children's Hospital, Temple, TX, USA

${ }^{4}$ Professor, Division of Adolescent Medicine, Children's Hospital Los Angeles and Department of Pediatrics, Keck School of Medicine, University of Southern California, Los Angeles, CA, USA

${ }^{5}$ Clinical Research Fellow, Southern California Permanente Medical Group, Kaiser HospitalPanorama City, Panorama City, CA, USA

${ }^{6}$ Senior Research Manager, Division of Adolescent Medicine, Children's Hospital Los Angeles, Los Angeles, CA, USA

${ }^{7}$ Associate Professor, Division of Adolescent Medicine, Children's Hospital Los Angeles and Department of Pediatrics, Keck School of Medicine, University of Southern California, Los Angeles, CA, USA

\section{Competing interests None}

Ethics approval Committee on Clinical Investigations, Children's Hospital Los Angeles, Los Angeles, CA, USA.

Provenance and peer review Not commissioned; externally peer reviewed. 


\section{REFERENCES}

1 Trussell J, Stewart F, Guest F, et al. Emergency contraceptive pills - a simple proposal to reduce unintended pregnancies. Fam Plann Perspect 1992;24:269-273.

2 Polis CB, Grimes DA, Schaffer K, et al. Advance provision of emergency contraception for pregnancy prevention. Cochrane Database Syst Rev 2007;2:CD005497.

3 Cheng L, Che Y, Gülmezoglu AM. Interventions for emergency contraception. Cochrane Database Syst Rev 2012;8:CD001324.

4 Daniels K, Jones J, Abma J. Use of emergency contraception among women aged 15-44: United States, 2006-2010. NCHS Data Brief No. 112, February 2013.

5 Dehlendorf C, Rodriguez MI, Levy K, et al. Disparities in family planning. Am J Obstet Gynecol 2010;202:214-220.

6 Wilkinson TA, Fahey N, Suther E, et al. Access to emergency contraception for adolescents. JAMA 2012;307:362-363.

7 Widman L, Welsh DP, McNulty JK, et al. Sexual communication and contraceptive use in adolescent dating couples. J Adolesc Health 2006;39:893-899.

8 Nguyen BT, Zaller N. Male access to over-the-counter emergency contraception a survey of acceptability and barriers in Providence, Rhode Island. Womens Health Issues 2009;19:365-372.

9 Cohen A, Bruno M, Grimm M, et al. Male knowledge of emergency contraception (EC) and influence on female partner's use. Paper presented at the American Public Health Association Conference, San Francisco, CA, USA, 27-31 October 2012.

10 Salganicoff A, Wentworth B, Ranji U. Emergency Contraception in California: Findings from a 2003 Kaiser Family Foundation Survey. Menlo Park, CA: The Henry J. Kaiser Family Foundation; February 2004. http:// kaiserfamilyfoundation.files.wordpress.com/2013/01/ emergency-contraception-in-california.pdf [accessed 10 October 2013].

11 Marcell AV, Waks AB, Rutkow L, et al. What do we know about males and emergency contraception? A synthesis of the literature. Perspect Sex Reprod Health 2012;44: 184-193.

12 Gold MA, Sucato GS, Conard LA, et al. Provision of emergency contraception to adolescents. J Adolesc Health 2004;35:67-70. 